\title{
Los clásicos españoles en el Romanticismo inglés: el caso de Lope de Vega y La hermosura de Angélica en Letters Written During a Short Residence in Spain and Portugal de Robert Southey*
}

\author{
CRISTINA FLORES \& JONATHAN GONZÁLEZ \\ Universidad de La Rioja
}

I

El Poeta Laureado Robert Southey (1774-1843), relevante y prolífico escritor inglés, no ha recibido hasta el momento la debida atención por parte de la academia a pesar de que para sus contemporáneos fue una figura central en los círculos culturales y literarios más influyentes de su país. Conocido como el tercero de los poetas Lakistas, junto con William Wordsworth y Samuel Taylor Coleridge, su producción literaria es muy extensa y abarca un amplio abanico de géneros que van desde poemas, obras dramáticas, ensayos y biografías, hasta narrativas de viajes e históricas. Curiosamente, a pesar de su relevancia en los círculos románticos ingleses, algunas de sus obras aún no se encuentran disponibles en una edición crítica moderna. Afortunadamente, esta situación se está revirtiendo en los últimos años y Southey ha comenzado a recibir la atención académica y editorial que merece. Como resultado, las primeras ediciones críticas de sus obras están viendo la luz de la mano de la editorial Pickering and Chatto, más tarde Routledge, en la serie 'The Pickering Masters', que ha publicado en la última década toda su poesía en varios volúmenes, seguidas de las más recientes ediciones de Letters from England by Don Manuel Alvarez Espriella (1807) y Sir Thomas More: or, Colloquies on the Progress and Prospects of Society

* Este trabajo es fruto de la investigación realizada en el marco del Proyecto BITAE (FFI2013-47806-R) financiado por el Ministerio de Economía y Competitividad del Gobierno de España, y está vinculado a un contrato de investigación FPI-UR/CAR (BOR-A-20170510III-1137) cofinanciado por el Gobierno de La Rioja y la Universidad de La Rioja. 
(1829). ${ }^{1}$ Además, en la actualidad, sus cartas privadas están siendo editadas y publicadas progresivamente on-line. ${ }^{2}$ Estas ediciones críticas de sus obras y correspondencia privada van ligadas a la creciente publicación de monográficos sobre su vida, obra y contexto. ${ }^{3}$ Por último, otro ejemplo de la relevancia y actualidad de los trabajos sobre este autor es el monográfico especial de la revista Romanticism on the Net dedicado a Robert Southey. ${ }^{4}$

Este reciente interés en el estudio de la vida y obra de Southey ha dejado al descubierto un aspecto de este polifacético autor que aún no ha recibido la suficiente atención: su fascinación por España. La pasión que Southey sentía por la cultura, lengua y literatura española le llevaría a convertirse en uno de los principales hispanistas de la era romántica en Inglaterra, solo rivalizado por Lord Holland. ${ }^{5}$ Southey leyó extensamente obras literarias españolas. De hecho, tal y como subraya Thomas De Quincey en Reminiscences of the English Lake Poets, una serie de ensayos publicados originalmente en Tait's Edinburgh Magazine en la década de 1830, la biblioteca personal de Southey contaba con los clásicos esenciales, además de

1 Robert Southey, Poetical Works 1793-1810, ed., intro. \& notes by Lynda Pratt, Tim Fulford \& Daniel Sanjiv Roberts, 5 vols (London: Pickering \& Chatto, 2004); Robert Southey, Later Poetical Works, 1811-1838, ed., intro. \& notes by Lynda Pratt, Tim Fulford, Carol Bolton, Ian Packer, Diego Saglia, Daniel E. White \& Rachel Crawford, 4 vols (London: Pickering \& Chatto, 2012); Robert Southey, Letters from England by Don Manuel Alvarez Espriella, ed., intro. \& notes by Carol Bolton (Abingdon: Routledge, 2016); y Robert Southey, Sir Thomas More: or, Colloquies on the Progress and Prospects of Society, ed., intro. \& notes by Tom Duggett \& Tim Fulford, 2 vols (Abingdon: Routledge, 2017).

2 Robert Southey, The Collected Letters of Robert Southey: A Romantic Circles Electronic Edition, general editors Lynda Pratt, Tim Fulford \& Ian Packer, 9 vols (Maryland: Univ. of Maryland/Romantic Circles Electronic Editions, 2009-); disponible en línea $<$ http://www.rc.umd.edu/editions/southey_letters> (último acceso 2 de noviembre de 2018).

3 Tales como: Robert Southey and the Contexts of English Romanticism, ed. Lynda Pratt (London: Ashgate, 2006); William. A. Speck, Robert Southey: Entire Man of Letters (New Haven: Yale U. P., 2006); o Stuart Andrews, Robert Southey: History, Politics, Religion (New York: Palgrave Macmillan, 2011).

4 Romanticism on the Net, 68-69 (2017), ed. Tim Fulford \& Matthew Sangster; disponible en línea <https://ronjournal.org/articles/n68-69/> (último acceso 2 de noviembre de 2018).

5 El papel de Henry Richard Vassal Fox (1773-1840), tercer barón Holland, como uno de los mayores hispanistas de su época en Gran Bretaña queda patente a la luz de la impresionante biblioteca de textos españoles que reunió en su mansión londinense, Holland House. Ésta destacaba especialmente por su casi media docena de manuscritos originales del puño y letra de Lope de Vega, junto y un gran número de primeras ediciones de sus obras. El interés de Holland por la figura del Fénix derivó en la publicación de su estudio crítico sobre la vida y obra del español en 1806, Some Account of the Life and Writings of Lope Felix de Vega Carpio, publicada de nuevo en 1817 como una edición revisada y expandida, que incluía un segundo volumen dedicado a Guillén de Castro-ambas ediciones fueron reseñadas por Southey para el Annual Review y el Quarterly Review en 1807 y 1818 respectivamente. Sobre la importancia de Holland House y su biblioteca para la promoción cultural y política de España en suelo británico, véase Will Bowers, 'The Many Rooms of Holland House', en Reevaluating the Literary Coterie, 1580-1830: From Sidney to Blackwood's, ed. Will Bowers \& Hannah Leah Crummé (New York: Palgrave Macmillan, 2016), 159-80. 
con un buen número de manuscritos de literatura inglesa, española y portuguesa. ${ }^{6} \mathrm{Su}$ relevante contribución en la diseminación de la historia, cultura y literatura española le hizo merecedor de ser nombrado miembro honorífico tanto de la Real Academia Española como de la Real Academia Española de la Historia en 1814 y 1815 respectivamente. ${ }^{7}$ Southey mostraría en numerosas ocasiones lo satisfecho que se sentía por dichos nombramientos:

This delay gives me an opportunity of cancelling the title page, for the purpose of inserting in it my new title of 'Member of the Royal Spanish Academy'-the Real Academia Española having been pleased to elect me an Academico Honorario, - of which honour the Secretary has sent me official annunciation under the great seal of the Academy-I have deserved this \& am gratified by it accordingly. In due time the Portugueze Academy will probably do the same thing. ${ }^{8}$

De un modo similar, en otra misiva de 1815 Southey se enorgullece de que 'my friends in Spain have just made me Member of a second Academythe R. Academy of History, - one of the most thoroughly erudite \& active bodies in Europe'. ${ }^{9}$ En una carta de 1816 el poeta inglés comentaba brevemente las pequeñas obligaciones que conllevaba la afiliación honorífica a sendas academias: 'My Spanish honours bring me into a curious dilemma; - as a Member of their two Academies I am expected to send copies of whatever I may publish to each'. ${ }^{10}$ Para Southey, que se consideraba a sí mismo 'half a Spaniard',11 estos nombramientos supusieron uno de sus mayores logros académicos: 'I am much gratified by the compliment the Academy have paid me, \& if the Lisbon Academy should follow the example

6 'The library-the collections of books, I mean, which formed the most conspicuous part of its furniture within-was in all senses a good one. The books were chiefly English, Spanish, and Portuguese; well selected, being the great cardinal classics of the three literatures; fine copies, and decorated externally with a reasonable elegance, so as to make them in harmony with the other embellishments of the room. This effect was aided by the horizontal arrangement upon brackets, of many rare manuscripts-Spanish or Portuguese' (Thomas De Quincey, 'Lake Reminiscences, from 1807 to 1830. By the English Opium-Eater. Southey, Wordsworth, and Coleridge', Tait's Edinburgh Magazine, 6 [1839], 513-17 [p. 514]).

7 Según las Memorias de la Real Academia Española, Southey fue el académico honorario número 47 en toda la historia de la institución, admitido oficialmente el 2 de junio de 1814. De un modo similar, en las Memorias de la Real Academia de la Historia, dentro del listado de académicos honorarios, se recoge que el 'Sr. D. Roberto Southey, poeta laureado de la Corte de Inglaterra' fue nombrado miembro honorífico de la misma el 23 de diciembre de 1814. Véanse Memorias de la Academia Española, vol. 1 (Madrid: M. Rivadenevra, 1870), 53; y Memorias de la Real Academia de la Historia, vol. 5 (Madrid: Sancha, 1817), lxviii.

8 The Collected Letters of Robert Southey, ed. Pratt, Fulford \& Packer, IV, 2529.

9 The Collected Letters of Robert Southey, ed. Pratt, Fulford \& Packer, IV, 2618.

10 The Collected Letters of Robert Southey, ed. Pratt, Fulford \& Packer, V, 2722.

11 The Collected Letters of Robert Southey, ed. Pratt, Fulford \& Packer, V, 3119. 
I should desire no other mark of literary honour'. ${ }^{12}$ De hecho, este honor era para el autor inglés equiparable a su cargo como Poeta Laureado. Originalmente Southey incluye en la primera página de sus obras poéticas, debajo de su cargo de Poeta Laureado, su nombramiento como 'Member of the Royal Spanish Academy [and] of the Royal Spanish Academy of History'. Aunque a partir de 1820 aclara que se trata de una afiliación honorífica. En las portadas de los tres volúmenes de su History of the Peninsular War (18231832), por ejemplo, señala que es 'Honorary Member of the Royal Spanish Academy, [and] of the Royal Spanish Academy of History'. ${ }^{13}$ Su interés por las letras españolas y su objetivo de difundirla entre sus compatriotas le llevó a publicar Amadis of Gaul (London: T. N. Longman \& O. Rees, 1803) y Chronicle of the Cid (London: Longman, Hurst, Rees \& Orme, 1808), traducciones de sendas obras medievales españolas.

Es en este aspecto de hispanista, aún sin explorar suficientemente, en el que se aventura el presente artículo. Este trabajo se enmarca en una línea de investigación emergente, la del estudio de las relaciones literarias y culturales anglo-españolas durante el periodo romántico inglés. Esta línea que inauguró sólidamente Diego Saglia con su magnífico trabajo Poetic Castles in Spain, ha dado lugar a interesantes monográficos como el de David Howard con un marcado enfoque histórico y cultural, o los de Joselyn Almeida, Susan Valladares, Diego Saglia e Ian Haywood, o el volumen actualmente en preparación editado por Agustín Coletes y Alicia Laspra, que analizan las conexiones literarias hispano-británicas. ${ }^{14} \mathrm{~A}$ pesar de todo, hay un aspecto que aún presenta muchas lagunas y que requerirá nuevos esfuerzos de investigación; nos referimos a la discusión sobre el lugar ocupado por los clásicos españoles en el Romanticismo inglés. Ya se ha señalado, por ejemplo, la presencia de Miguel de Cervantes, especialmente de su obra universal Don Quijote, en Samuel Taylor Coleridge y William Wordsworth. Asímismo, el espectro de autores españoles presentes en obras de poetas románticos se ha ampliado a otras figuras como Santa Teresa de Ávila y Pedro Calderón de la Barca, en el caso de Coleridge. ${ }^{15}$ Sin embargo,

12 The Collected Letters of Robert Southey, ed. Pratt, Fulford \& Packer, IV, 2529.

13 Robert Southey, History of the Peninsular War, 3 vols (London: John Murray, 18231832).

14 Diego Saglia, Poetic Castles in Spain: British Romanticism and Figurations of Iberia (Amsterdam/New York: Rodopi, 2000); David Howarth, The Invention of Spain. Cultural Relations between Britain and Spain, 1770-1870 (Manchester: Manchester U. P., 2007); Romanticism and the Anglo-Hispanic Imaginary, ed. Joselyn Almeida (Amsterdam/New York: Rodopi, 2010); Susan Valladares, Staging the Peninsular War: English Theatres 1807-1815 (Abingdon: Routledge, 2015); Spain in British Romanticism 1800-1840, ed. Diego Saglia \& Ian Haywood (New York: Palgrave Macmillan, 2018); and Romanticism, Reaction and Revolution: British Views on Spain, 1814-1823, ed. Agustín Coletes \& Alicia Laspra (Berne: Peter Lang, 2019).

15 Edward Sarmiento, 'Wordsworth and Don Quijote', BHS, XXXVIII:1 (1961), 113-19;

Beatriz González Moreno, 'Visiones de Don Quijote en el Romanticismo Inglés', en 'Don Quijote' por tierras extranjeras: estudios sobre la recepción internacional de la novela 
aún queda mucho por investigar sobre la recepción de los clásicos españoles en la Inglaterra romántica y su contribución a la construcción del movimiento romántico inglés. Curiosamente es Robert Southey, miembro honorífico de la Real Academia, el autor que menos atención ha recibido a este respecto y eso que, además de ser un gran conocedor de la literatura española, también ejerció como difusor de dicha literatura entre sus colegas Lakistas. Sirva como ejemplo, tal y como señala María Eugenia Perojo Arronte, que Coleridge leyó alguna obra española a través de las traducciones de Southey, como es el caso de Chronicle of the Cid, o en volúmenes que este último le prestó, como su copia de las obras de Santa Teresa de Jesús traducidas al inglés. ${ }^{16}$ En este contexto, Southey surge como un elemento crucial en el estudio de la recepción de los clásicos españoles en la Inglaterra de la época romántica. A este respecto, es importante señalar que, a pesar de que hay una serie de trabajos que analizan el papel de Southey como traductor de obras literarias españolas, ${ }^{17}$ hasta la fecha, solo un par de publicaciones, a las que acudiremos más adelante en nuestro trabajo, se detienen a explorar la recepción de Lope en el escritor inglés. ${ }^{18}$

Por otro lado, también sorprende la falta de trabajos de investigación que estudien la pervivencia de Lope de Vega en Inglaterra. Sí existen trabajos que exploran la presencia del escritor canónico español en Francia,

cervantina, ed. Hans Christian Hagendom (Cuenca: Univ. de Castilla-La Mancha, 2007), 20315; María Eugenia Perojo Arronte, 'Samuel Taylor Coleridge on Don Quixote', Cervantes. Bulletin of the Cervantes Society of America, 34 (2014), 203-18; and María Eugenia Perojo Arronte, 'Coleridge and Spanish Literature', en Spain in British Romanticism 1800-1840, ed. Saglia \& Haywood, 95-114.

16 Perojo Arronte, 'Coleridge and Spanish Literature', 113. Coleridge y Southey leyeron una traducción de Abraham Woodhead, titulada Works of the Holy Mother St Teresa of Jesus, y publicada entre 1669 y 1675 . Se trata de una versión inglesa de la autobiografía de Santa Teresa de Jesús escrita entre 1562-1565 y publicada poco después de su muerte en 1588: Los libros de la madre Teresa de Jesús, fundadora de los monasterios de monjas y frailes carmelitas descalzos de la primera regla, editada por Fray Luis de León.

17 J. L. Chamosa González \& T. Guzmán González, 'Robert Southey, traductor de poesía española', en Actas de la I Jornadas Nacionales de Historia de la Traducción, ed. Julio César Santoyo (León: Univ. de León, 1987), 340-48; Juan Miguel Zarandona, 'Robert Southey: hispanista y traductor de obras clásicas castellanas medievales', Revista de Investigación. Filologia, 2:1 (1993-1994), 7-27; y Juan Miguel Zarandona, 'The Amadis of Gaul (1803) and The Chronicle of the Cid (1808) by Robert Southey: The Medieval History of Spain Translated', en Charting the Future of Translation History, ed. Georges L. Bastin \& Paul F. Bandia (Ottawa: Univ. of Ottawa Press, 2006), 309-32.

18 Juan Miguel Zarandona, 'Las leyendas de España de El último godo de Lope de Vega y los versos románticos sobre Don Rodrigo de los británicos Walter Scott y Robert Southey, y del español José Zorrilla', en El patrimonio del teatro clásico español: actualidad y perspectivas, ed. Germán Vega, Héctor Urzaiz \& Pedro Conde (Valladolid: Univ. de Valladolid, 2015), 749-61; y Jonathan González, 'Poetic Industry and Abominable Superstition: Southey on Lope de Vega', Romanticism on the Net, 68-69 (2017), 1-30; disponible en línea $<$ https://ronjournal.org/articles/n68-69/poetic-industry-and-abominable-superstition-southeyon-lope-de-vega/> (último acceso 2 de noviembre de 2018). 
especialmente durante el siglo XVII, ya que su influencia se considera esencial en la formación del teatro clásico francés. ${ }^{19} \mathrm{Y}$, por supuesto, bien conocida es la recepción del Teatro del Siglo de Oro español en el pensamiento romántico alemán, especialmente en A. W. Schlegel. Pero, hasta lo que sabemos, no han sido publicados trabajos que analicen la presencia del Fénix en Inglaterra a excepción de los mencionados en el párrafo anterior. ${ }^{20}$

Con todo, este artículo pretende ser el primer estadio de un proyecto más amplio que analice de manera detallada la presencia de Lope en la obra de Southey a lo largo de toda su carrera. Aquí nos ceñiremos a una primera etapa, la comprendida los años 1797 y 1817, y a una obra en concreto, la primera edición de Letters Written During a Short Residence in Spain and Portugal. With Some Account of Spanish and Portugueze Poetry. ${ }^{21}$ Nuestro interés se centra en la visión de España, su cultura, tradiciones y literatura, que el joven Southey ofreció a sus compatriotas a través de su narrativa de viaje epistolar, publicada por primera vez en 1797, tras pasar seis meses viajando en la Península Ibérica. Y aún más concretamente, el objetivo de este trabajo es el de analizar el retrato de Lope de Vega y su poema épico $L a$ hermosura de Angélica que el escritor inglés dibuja en las páginas de Letters.

En esta obra, el interés de su autor por el Fénix de los ingenios va más allá de la crítica literaria. Cuestiones políticas y religiosas tiñen los comentarios del inglés sobre la obra y vida del dramaturgo y poeta español. De esta manera, Southey se sitúa como figura esencial para entender el diálogo anglo-español a finales del siglo XVIII y comienzos del XIX. Asimismo, con este trabajo pretendemos mostrar la presencia y relevancia de Lope de Vega más allá de las fronteras españolas y dar un primer paso en el estudio de la recepción internacional del Fénix de los ingenios.

\section{II}

Tal y como señala González, las primeras alusiones de Southey a Lope de Vega aparecen en su correspondencia privada en 1793. ${ }^{22}$ En ellas, hace continuas referencias a Lope como uno de los escritores más productivos de la historia de la literatura universal. De esta manera se hace eco de una

19 Véase Francesca Suppa, 'La última traducción prerromántica del teatro de Lope en Francia: el Théâtre Espagnol de Linguet', Anuario Lope de Vega. Texto, Literatura, Cultura, XXIII (2017), 131-54 (p. 139).

20 Con la salvedad de una brevísima anotación en el trabajo de Victor Dixon, 'Una mirada rápida sobre el teatro del Siglo de Oro español en Gran Bretaña e Irlanda', en El patrimonio del teatro clásico español: actualidad y perspectivas, ed. Germán Vega, Héctor Urzáiz \& Pedro Conde (Valladolid: Univ. de Valladolid, 2015), 139-40.

21 A falta de una edición moderna, usamos la primera edición: Robert Southey, Letters Written During a Short Residence in Spain and Portugal. With Some Account of Spanish and Portugueze Poetry (Bristol: Joseph Cottle, 1797). Por economía, a partir de ahora nos referiremos a la obra bajo estudio aquí como Letters. Todas las citas en el texto corresponden a esta edición.

22 González, 'Poetic Industry and Abominable Superstition', 4. 
visión de Lope muy extendida, y superar cuantitativamente a Lope en producción literaria se convierte en un reto a perseguir para el joven Southey. Sin embargo, Lope comienza a tener más protagonismo en su correspondencia a partir de finales de 1796, coincidiendo con una serie de cartas públicas que el joven poeta publicó en el Monthly Magazine sobre la poesía española y portuguesa y, sobre todo, a partir de la publicación de sus Letters en 1797. Este interés por el Fénix alcanzo su punto álgido en 1818, cuando Southey publicó un extenso artículo en el Quarterly Review sobre la segunda edición de la prestigiosa obra de Lord Holland, Some Account of the Life and Writings of Lope Felix de Vega y Carpio, de cuya primera edición ya había escrito una reseña en 1807 para el Annual Review. ${ }^{23}$ El impacto de la lectura de Lope en Southey se hace evidente tanto en la segunda edición de Joan of Arc (1798) como en Roderick, The Last of the Goths (1814), en las que Southey introdujo extensas notas explicativas en las que señalaba y incluso citaba pasajes del poema Jerusalén conquistada (1609) de Lope de Vega.

Southey llegó a conocer en profundidad todas las facetas literarias de Lope, aunque mostró predilección por su vertiente poética. Y eso a pesar de que era conocedor de sus obras dramáticas. En concreto, Southey estudió con profundidad algunas de sus piezas teatrales, tales como La estrella de Sevilla (1623), y su admiración llegó al punto de que la obra de Lope El último godo de España (1617) le sirvió al inglés como fuente de inspiración en la creación de su poema épico Roderick, The Last of the Goths (1814). ${ }^{24}$ También leyó y coleccionó dos ejemplares de El peregrino en su patria (1604), una novela bizantina con la que Lope dio paso al periodo de esplendor de este género y que, en esta ocasión, tiene un importante carácter dramático, puesto que el Fénix inserta cuatro autos sacramentales completos, uno tras cada uno de los cuatro primeros capítulos de la novela: Viaje del Alma, Bodas entre el Alma y el Amor Divino, La Maya e Hijo pródigo. ${ }^{25}$

23 El estudio de Holland aúna una compleja combinación de biografía, textos líricos y dramáticos, y numerosas traducciones, que contribuyó al gusto por los temas españoles predominante en Gran Bretaña durante el período romántico y que, junto con el trabajo de Southey, promovió una gran expansión en el interés por Lope a fines de la época georgiana y durante la era victoriana.

24 The Collected Letters of Robert Southey, ed. Pratt, Fulford \& Packer, IV, 2309. Véase también [Robert Southey], 'Some Account of the Life and Writings of Lope Felix de Vega Carpio by Henry Richard Lord Holland', en The Annual Review and History of Literature; for 1806, ed. Arthur Aikin (London: Longman, Hurst, Rees \& Orme, 1807), 397-411 (pp. 409-11).

25 Se trata de los núms 3672 y 3762 recogidos en el catálogo de la biblioteca de Southey: un ejemplar del siglo XVII publicado en Madrid en 1618 por la viuda de Alonso Martin a costa de Alonso Pérez, y un volumen del siglo XVIII encuadernado en cuero, publicado en 1733 también en Madrid por Francisco Martínez Abad. Véase Leigh Sotheby, Catalogue of the Valuable Library of the Late Robert Southey, Esq., Ll.d., Poet Laurate (London: Leigh Sotheby \& Co., 1844), 195 \& 200. Antes de hacerse con estas dos ediciones, Southey trabajó en profundidad con la copia de El peregrino en su patria albergada en la biblioteca de Holland House (The Collected Letters of Robert Southey, V, 3021 \& VI, 3566). Sobre los autos sacramentales de esta novela bizantina, véase Emilia Deffis de Calvo, 'Los autos 
González muestra en su artículo lo difícil que resulta evaluar la contribución de Southey a la crítica sobre el Fénix de los Ingenios, debido a su permanente ambivalencia. ${ }^{26}$ En un periodo de veinte años, Southey pasó de condenar cómo 'the dangerous abilities of Lope de Vega assisted the progress of evil' (Letters, 127), a convertirse en un entusiasta empedernido del autor español,

[...] heartly wish[ing] that I had the collected edition of Lope de Vega,-I have a good many of his works separately, in the original editions,--but it would be much more satisfactory to possess the whole. ${ }^{27}$

Incluso cuando su objetivo era alabar el genio poético de Lope, Southey siempre encontraba lugar para algún ataque basado en el supuesto catolicismo de algunos de sus versos. Sin embargo, es importante notar que la ambigüedad y la ambivalencia son características idiosincráticas del autor inglés y que no se debe tanto a las obras de Lope como a la personalidad de quien escribe sobre su obra. Lynda Pratt ha señalado que 'his [Southey's] career was characterised by ambiguity' y que 'Southey's life and works are, [...] marked by paradox and contradiction, by their scale of indeterminacy'. ${ }^{28}$ En lo que sigue nos centraremos en la opinión sobre Lope que Southey plasma en un momento muy concreto, en 1797, en sus Letters.

\section{III}

El 8 de diciembre de 1795, acompañado por su tío, Robert Southey embarca en el puerto de Falmouth con destino a La Coruña, donde desembarcó cinco días más tarde. El joven poeta inició su periplo por la Península Ibérica sumido en una profunda tristeza que, sin duda, tiñó su percepción de la tierra y las gentes que conoció durante los seis meses que duró su viaje. Southey comenzó su aventura con cierta aprensión por su miedo a morir ahogado durante la travesía; imbuido en la nostalgia que le producía la separación de su esposa Edith, con quien había contraído nupcias secretamente unos días antes de embarcar, además de entristecido por la carta de despedida, cargada de reproches, con la que Coleridge daba por terminada su amistad. El poeta inglés viajó de La Coruña a Madrid antes de dirigirse a Lisboa a pie y en carruaje, llegando a la capital lusa el 27 de enero de 1796, después de haber pasado más de un mes y medio en España. El 5 de mayo de 1796 embarcó en

\footnotetext{
sacramentales de El peregrino en su patria de Lope de Vega', en El escritor y la escena VI. Estudios sobre el teatro español y novohispano de los Siglos de Oro, ed. Ysla Campbell (Ciudad Juárez: Univ. Autónoma de Ciudad Juárez, 1998), 85-97.

26 González, 'Poetic Industry and Abominable Superstition', 18-23.

27 The Collected Letters of Robert Southey, ed. Pratt, Fulford \& Packer, V, 3021.

28 Lynda Pratt, 'Introduction', en Robert Southey and the Contexts of English Romanticism, ed. Pratt, xvii-xxix (pp. xxv \& xxii).
} 
Lisboa con destino a Porstmouth, finalizando así su primer viaje por España y Portugal. ${ }^{29}$

Siguiendo la moda emergente de las narraciones de viajes, Southey da cuenta de su periplo por la Península Ibérica en Letters Written During a Short Residence in Spain and Portugal. Este viaje fue sin duda motivado por su ambivalente interés por todo lo extranjero. En palabras de Lynda Pratt:

Southey was both fascinated and repelled by the foreign and the exotic. One of the leading Hispanists of the period, he was in addition an important figure in the development of early nineteenth-century imperial and orientalist ideologies. His preoccupations ranged from late eighteenth-century Spain to Incan Peru, posadas to pagodas, Roman Catholic ritual to American Indian ceremonies, transubstantiation to blood sacrifice. Moreover, his preoccupation with a foreign 'Other' encompasses his poetry and prose, the works of his early, middle and late career. ${ }^{30}$

Las Letters son un claro ejemplo de su profundamente ambiguo cosmopolitismo cultural. En ellas vemos cómo Southey sentía a la vez fascinación y repulsión por todo lo foráneo. El 'Otro', en este caso España y Portugal, se dibuja en Letters en contraste con su país de origen. La exploración y definición del 'Otro' es una característica esencial de las narrativas de viaje. Este género literario proliferó durante el siglo XVIII y se convirtió en un género de gran prestigio y popularidad. Los lectores se acercaban a estas obras tanto por entretenimiento como para instruirse. ${ }^{31}$ Sin embargo, las Letters se diferencian de otras narrativas de viaje de la época por reflejar un interés mayúsculo hacia la literatura de los países visitados. En este caso, el viajero es además un poeta romántico y, como consecuencia, reacciona ante todo lo visto y vivido con una especial sensibilidad poética. El viaje a pie o paseo, denominado pedestrianismo, se convirtió en un motivo central en la poesía romántica que ha dado lugar a numerosos estudios. ${ }^{32}$ Además, durante los seis meses que paso en la Península, Southey se dedicó al estudio de la poesía española y portuguesa, aunque con una clara inclinación hacia la primera. De dicho estudio dejó amplia constancia en su narración. De ahí que el título de Letters contenga el subtítulo With Some Account of Spanish and Portugueze Poetry, que hace referencia el 'Essay on the Poetry of Spain and Portugal' incluido en medio de la narración. El joven poeta tenía el firme convencimiento de que: 'books

29 Speck, Robert Southey: Entire Man of Letters, 60-61.

30 Pratt, 'Introduction', en Robert Southey and the Contexts of English Romanticism, ed. Pratt, xxvi.

31 Carl Thompson, Travel Writing (London: Routledge, 2011), 45.

32 Véase Robin Jarvis, Romantic Writing and Pedestrian Travel (Basingstoke: Macmillan/New York: St Martin's Press, 1997); y Jeffrey C. Robinson, The Walk: Notes on a Romantic Image (Norman: Univ. of Oklahoma Press, 1989). 
are the portrait of the public mind, and the characteristic traits of every age and of every people may be read in their poetry' (Letters, 129-30). Así, Southey incluye en su narrativa un ensayo sobre la poesía española y portuguesa titulado 'An Essay on the Poetry of Spain and Portugal', además de una selección de poemas de ambas nacionalidades en su idioma original, acompañados de su propia traducción al inglés, que se distribuyen a lo largo de toda la obra. Con respecto a las traducciones, Southey admite en el prefacio a las Letters que las ha elaborado con libertad, aunque también incluye los originales a continuación de sus traducciones para hacerles debida justicia: 'My poetical imitations are made with freedom, but I have always done justice to the originals by annexing them [...]. Where I have copied from early writers, the early spelling is preserved' (Letters, v). A estos poemas hay que añadir aquellos que él mismo compone, al estilo de la poesía pedestre romántica, como resultado de su viaje.

En la siguiente tabla hemos reunido la información que aparece en el 'índex' de poesía, que sigue a la lista de contenidos en Letters, y hemos completado la información, cuando faltaba, sobre el título, la autoría (nombre completo y fechas) e idioma del original:

\section{<INSERT TABLE 1 HERE BELOW THIS HEADING>}

Tabla 1

Relación de autores y obras poéticas citadas y traducidas en Letters (1797) ${ }^{33}$

Según se puede observar en la tabla, el número de poemas españoles citados y traducidos por Southey supera ampliamente al de los escritos originalmente en portugués. El autor ofrece al lector inglés poemas de los españoles Tomás Iriarte, George de Montemayor, ${ }^{34}$ Lope de Vega, Fray Luis de León, Esteban Manuel de Villegas, Alonso de Ledesma, Bartolomé Leonardo de Argensola, Luis de Góngora y Francisco de Quevedo; mientras que solo hay cuatro autores portugueses con presencia en las Letters: Jeronimo Baía, Pedro Azevedo Tojal, Francisco Manuel de Melo y Frei José

33 No incluimos en la tabla los poemas originales compuestos por Robert Southey por no ser el objeto central de estudio en este trabajo: 'Retrospective Musings', 'Lines Written on Monte Salgueiro', 'Sonnet: Another mountain yet! I thought this brow', 'Lines upon the Widow of Villa Franca', 'Lines upon Christmas Day', 'Inscription for a Monument, where Juan de Padilla Suffered Death', 'Inscription for a Column at Truxillo, 'Ode: When at morn, the muleteer', y 'Musings after visiting the Convent of Arrabida'. Estos poemas han sido editados recientemente en Southey, Poetical Works 1793-1810, ed. Pratt, Fulford \& Roberts, V, 13852 .

34 O Jorge de Montemayor. Aunque de nacionalidad portuguesa, escribió en español. 
de Santa Rita Durao. Si a esto le sumamos que el número de versos citados y traducidos es muy superior en el caso de los poemas españoles, no queda duda de la preferencia de Southey por la literatura española y, en concreto, por la obra de Lope de Vega. Southey admite abiertamente su preferencia por las letras españolas en Letters cuando dice:

The Spanish poets please me better than the Portugueze; they possess more dignity, and they are not infected by that national vanity which characterises their neighbours, and which, though it may be very patriotic, is very ridiculous. (Letters, 373)

Esta preferencia es aún más evidente cuando, hablando de la literatura portuguesa, Southey afirma: 'we may seek in vain to equal the wit of Quevedo, the genius of Luis de Leon, and the sententious strength of the Leonardos' (Letters, 374). Y mientras que el español Villegas es para Southey: 'perhaps the most elegant of the Spanish writers' (Letters, 374), el portugués Francisco Manuel is but an indifferent poet' (Letters, 468).

De todos los autores citados en Letters, sobre los que apenas hace comentarios más allá de los que acabamos de mencionar arriba, el que más atención recibe es, sin duda, Lope de Vega. En Letters, Southey afirma conocer a Lope de tiempo atrás. Lo cierto es que, como ya hemos mencionado, el autor inglés hace alusiones al escritor español en su correspondencia privada en 1793, haciéndose eco de la fama del Fénix como el más prolijo de los autores. El joven Southey se enorgullecía entonces de haber escrito 'more than any author ever did at my age' con la idea de que en un par de años llegaría a superarle: 'out volume Lope de Vega'. ${ }^{35}$ Sin embargo, Southey no tuvo acceso directo a las obras de Lope hasta que no puso pie en España, y parece ser que éste era uno de los principales objetivos de su viaje, tal y como cuenta en Letters:

I have made progress enough in the language to talk about it very learnedly. Long acquainted with the name of Lope de Vega, you may suppose I eagerly made acquaintance with him as soon as it was in my power. Of his industry and genius you have heard enough in England: I will give you some specimens of his merit and manner, from which you may judge whether or no the character I draw of him be just.

(Letters, 119)

Seguidamente, Southey cita el soneto número XXXIX de Rimas, publicado por Lope de Vega por primera vez en 1602, como ejemplo del genio del español: ${ }^{36}$

35 The Collected Letters of Robert Southey, ed. Pratt, Fulford \& Packer, I, 71.

36 La transcripción que realiza Southey contiene algunos fallos de vocabulario y puntuación. Véase Lope de Vega, Rimas, ed. crítica \& anotada de Felipe B. Pedraza Jiménez, 2 vols (Ciudad Real: Univ. de Castilla-La Mancha, 1993-1994), II, Edición crítica de las 
Quando por este margen solitario

Villano agricultor os transponía

Verdes olmos, apenas yo sabia

Que fuesse honesto bien, ni mal contrario.

Treinta vezes el Sol al Sagitario

Saliendo de la casa humida y fría

Del Escorpion, toco desde aquel dia

Cursu inmortal de su camino vario.

Crecistes, y creci vuestra belleza,

Fue mi edad verde, como ya a mis danos

Espejo vuestra rigida corteza;

Los dos sin fruto, vemos sus enganos,

Mais ay que no era en vos naturaleza

Perdi mi tiempo-llorare mis danos. (Letters, 120)

Y a continuación, lo traduce:

Ye shadowy elms! When in this solitude

The rustic planted you, my infant mind

As yet unapt of reason, knew not good

From evil. Thirty winters has the wind

Stript from your trembling boughs the foliage fear,

And thirty times upon his radiant way

On you the Sun has pour'd his summer ray,

Gilding the foliage of the ripen'd year.

You beauty still has grown, and still it grows,-

Alas! my Youth has been! And now all dark

And sad of mind, a man of many woes,

I in the mirror of your wrinkled bark

Know mine own mournful image, and with tears

Reflect in anguish on my ill-spent years.

(Letters, 120-121; énfasis en el original)

Como señala Felipe B. Pedraza Jiménez, en este soneto Lope alude al reencuentro con los árboles de su infancia madrileña, los cuales el yo poético utiliza para explorar la inocencia de su niñez y el modo en el que el paso de los años de esos verdes olmos refleja su propio desarrollo vital. Sin embargo el Fénix concluye, por medio de una alusión velada al conocido refrán 'no hay que pedirle peras al olmo', que si bien los olmos de su infancia no han dado fruto, a pesar de si ser propio de los hombres madurar y ser fructíferos, esto no le ha ocurrido al poeta. ${ }^{37} \mathrm{Si}$ bien el escritor inglés no hace comentario alguno sobre este soneto, más allá de ofrecérselo al lector como un ejemplo

'Rimas' de Lope de Vega, 269. Entre ellos, destaca 'danos' en los versos 10 y 14, que en el original son 'años' y 'daños' respectivamente.

37 Lope de Vega, Rimas, ed. Pedraza Jiménez, II, 268. 
del genio de Lope, su elección es bastante significativa. ${ }^{38}$ Como la mayoría de los poemas españoles seleccionados por Southey para ser incluidos en su narrativa de viajes, este soneto está lleno de imaginería natural, que le habría atraído desde un primer momento dado el papel central que tiene la naturaleza en la poética romántica en general, y en su obra en particular. ${ }^{39}$ De hecho, para los románticos la contemplación e interacción con la naturaleza tiene un carácter máxime subjetivo, de modo que la interacción de estos escritores con el mundo natural y el modo en que éste se plasma en sus poemas, varía en función del propósito de sus versos o del estado de ánimo del poeta. ${ }^{40}$ Se trata de un recurso lírico que Lope prefigura en cierta medida en este soneto XXXIX de Rimas, y que sin duda constituye uno de los principales elementos que podrían haber llevado a Southey a elegirlo como un ejemplo de su 'industry and genius, [...] of his merit and manner' (Letters, 119).

Pero, en este caso, la síntesis entre el mundo natural y la vida del yo poético que queda plasmada en el soneto de Lope anticipa además la concepción romántica de esta comunión como una puerta de entrada hacia un estado emocional similar al de la infancia-'my infant mind' (Letters, 120), como Southey añade en su traducción. Y esto es especialmente relevante, pues dentro de la poética romántica la infancia es considerada como un estado espiritual que orbita en torno al mundo natural y la noción de eternidad, ofreciéndole al poeta la capacidad de descubrir algo nuevo y sublime en cada objeto y experiencia sensorial, que acaba revelándole la esencia de la naturaleza y la vida. Una idea que el también romántico inglés William Wordsworth resume en su dictum 'the Child is the father of the Man', y que paradójicamente tendrá un resurgimiento en la poesía española de principios de siglo XX, precisamente a través de estos autores ingleses. ${ }^{41}$ En este sentido, el acto de rememorar es el primer paso que ha de tomar el poeta, que da lugar a la explosión de sentimientos surgidos en la recreación de dichas emociones a través de la contemplación. 'Cuando por este margen solitario' guarda así, de hecho, un extraño parecido con un soneto que Southey había compuesto en noviembre de 1794, 'To a Brook Near the Village of Corston', y que revisó para su publicación en Poems (1797), una colección que vio la luz casi de manera simultánea a sus Letters. Este poema en el que Southey vuelve a visitar un arroyo situado cerca de la casa de su infancia, a raíz de lo cual su memoria dibuja 'the faint-formd scenes of the departed

38 Sería interesante hacer un análisis detallado de todas las traducciones realizadas por Southey en sus Letters, aunque este objetivo sobrepasa los límites del presente trabajo.

39 Véase Tim Fulford, The Late Poetry of the Lake Poets: Romanticism Revisited (Cambridge: Cambridge U. P., 2013), 29-68.

40 Stephen Hebron, The Romantics and the British Landscape (London: British Library, 2006), vii.

41 Cristina Flores, "Imported Seeds": The Role of William Wordsworth in Miguel de Unamuno's Poetic Renewal', en Romanticism and the Anglo-Hispanic Imaginary, ed. Joselyn M. Almeida (Amsterdam/New York: Rodopi, 2010), 249-74 (pp. 264-68). 
days', ${ }^{4}$ pertenece, de hecho, a una vertiente de poesía fluvial en la que varios poetas británicos de la década de 1780 y 1790 unificaron ideas sobre la visión retrospectiva de la infancia, la comunión con la naturaleza, la continuidad temporal y la herencia poética. ${ }^{43}$

De una manera similar a cómo Southey emplearía en su soneto la visita al paraje natural de su niñez para recrear una serie de emociones de los días pasados de su infancia, concluyendo con una reflexión sobre el impacto de este tiempo pasado en su yo actual, 'Dim are the long past days, yet still they please / As thy soft sounds half heard, borne on the inconstant breeze'; ${ }^{44}$ el yo poético de Lope en el soneto de Rimas usa la visión de aquellos verdes olmos madrileños treinta años después para recrear su infancia, de modo que la nueva realidad adquirida tras la remembranza le lleva reflexionar cómo es precisamente el tiempo perdido desde entonces lo que le ha conducido hasta su situación actual. Además de observar atisbos de la teoría sobre la naturaleza que promoverían los románticos, Southey habría visto como Lope dramatiza en estos versos, al igual que harían los poetas ingleses, el acto de recordar en tranquilidad como puerta de entrada a sus recuerdos de emociones pasadas, cuyo origen está precisamente en la infancia, y en su interacción con la naturaleza. De hecho, en su imaginería y elección de vocabulario, la traducción que Southey lleva a cabo del soneto del Fénix le confiere prominencia precisamente a la vinculación entre la infancia y la naturaleza como decisivas para el desarrollo físico y espiritual del yo poético, su 'infant mind / as yet unapt of reason' iluminando 'the foliage of the ripen'd year' (Letters, 120).

Tras la traducción de este poema en Letters con el que Southey ejemplifica el genio poético de Lope, encontramos 'An Essay on the Poetry of Spain and Portugal'. Con excepción de algunas referencias sueltas a la literatura portuguesa, la mayor parte del ensayo está dedicado a departir sobre literatura española, con Lope en el centro de la discusión:

The dangerous abilities of Lope de Vega assisted the progress of the evil. This prodigy of nature wrote for the multitude, and cared not for the critics; and strange indeed would it have been if the man who constantly wrote five sheets a day, did not in the rabble of his thoughts stumble upon some that were good. The wit and satire of Villegas and Cervantes were wasted against this careless yet lively versifier: the people flocked to his loose comedies, and bought his books: the money he rapidly acquired he liberally bestowed; the poet was admired and the man was beloved. (Letters, 127)

42 Southey, Poetical Works 1793-1810, ed. Pratt, Fulford \& Roberts, V, 87.

43 David Fairer, 'Southey's Literary History', en Robert Southey and the Contexts of English Romanticism, ed. Lynda Pratt (Aldershot: Ashgate, 2006), 1-18 (p. 16).

44 Southey, Poetical Works 1793-1810, ed. Pratt, Fulford \& Roberts, V, 88. 
Una vez más, Southey deja que su rechazo a la religión que el español profesaba tiña su opinión sobre la calidad literaria de las obras de Lope a quien, a pesar de que lo considera un prodigio de la naturaleza, también acusa de colaborar en el progreso del mal, de escribir versos pobres si bien numerosos, y comedias argumentalmente inconsistentes y moralmente libertinas-jugando con el doble sentido de 'loose comedies' (Letters, 127)que, sin embargo, cuentan con gran aceptación por parte del público. Paradójicamente, a pesar de que este retrato de Lope no es muy positivo, Southey lamenta a continuación la negligencia sufrida por los autores españoles y portugueses en su tierra natal:

It is strange that the literature of Spain and Portugal should have been totally neglected at this period, when these countries were in the meridian of their glory. Don Quixote, the Visions of Quevedo, the Spanish Rogue, and the Lazarillo de Tormes of the great Mendoza, are almost the only Spanish books that we have naturalised.

(Letters, 122)

El 'Essay' también resulta de especial interés para entender la permanente ambivalencia de Southey hacia el Fénix, puesto que su tesis principal se basa en la creencia de que el despotismo, superstición y ateísmo que tradicionalmente habían imperado en España habían mermado la capacidad literaria de los poetas españoles, de manera que nunca habían sido capaces de alcanzar tal nivel de perfección como los ingleses. De este modo, y a través del propio etnocentrismo de Southey, su discusión de las letras españolas se convierte en un tratado sobre la historia política y social de España, al mismo tiempo que aborda cuestiones sobre la naturaleza misma de la poesía:

To form the real Poet enthusiasm is necessary, and a consciousness of the dignity of his own nature; the one cannot exist in the bigot, and neither of them in the Atheist or in the contented slave of Despotism. Such then are the causes that have combined to prevent the progress of Poetry in Spain,- - the licentious negligence of their most favourite authors, the decline of the state, the despotism of the government, and an absurd and abominable superstition. (Letters, 129-30)

Como señala Carol Bolton, la airada condena que Southey realiza de la Iglesia Católica en Letters nace de su preocupación por el impacto social de sus doctrinas sobre el pueblo español, puesto que él sentía que el catolicismo dominaba las vidas las de los ciudadanos españoles para su detrimento. ${ }^{45}$ Así, si bien llegaría a ser considerado como 'the friend of Spain and Spanish

45 Carol Bolton, Writing the Empire: Robert Southey and Romantic Colonialism (London: Pickering \& Chatto, 2007), 216. 
literature', ${ }^{46}$ en las Letters Southey emplea la metáfora de la infección a la hora de tratar la cuestión religiosa en España-comparación que luego aplicaría a sus escritos sobre Italia, Irlanda, África, India y Sudamérica-por temor a que el contacto con ciertos aspectos de una cultura extranjera pudiera ser moralmente contagioso y dañino. ${ }^{47}$ La pandemia papista, tal y como Southey lo veía, frustraba el genio poético, su efecto principal sobre la mente del poeta siendo 'like that of those poisons on the body that produce death by a slow but certain operation' (Letters, 128). Sus intentos de distanciarse de la vertiente católica de la literatura española, especialmente en el caso de Lope, podrían verse como un intento de evitar cualquier tipo de contagio de las creencias religiosas del Fénix y el resto de literatos españoles. Con todo, y a pesar de argumentar que el despotismo y la superstición que imperaba en España habían mermado la poesía española, Southey concede enorme mérito a Lope y los poetas españoles en general, ya que labouring under so many disadvantages, it is rather to be wondered at that they have done so much, than that they have not accomplished more' (Letters, 130).

A este ensayo le sigue un estudio de La hermosura de Angélica que Southey titula 'Analysis of La Hermosura de Angelica, An Heroic Poem, By Lope de Felix de Vega Carpio'. La hermosura es un poema narrativo épico muy extenso que Lope compuso en imitación y como continuación de la obra Orlando furioso, de Ludovico Ariosto. Con este poema Lope, que era ya muy popular por sus obras de teatro, pretendía también ganar respeto y fama como escritor erudito. Bien es cierto que este cambio de registro pudo también ser motivado por una circunstancia ajena a su voluntad, ya que desde 1598 a 1600 el rey Felipe II suspendió las representaciones teatrales. En este contexto Lope, privado de su habitual modo de ganarse la vida, dirigió sus esfuerzos a crear poemas y prosa de carácter más culto, en su época de mayor influencia italiana. En 1602, La hermosura fue publicada junto con otros 200 sonetos de las Rimas y La Dragontea, otro trabajo erudito dedicado a la figura de Francis Drake. El volumen fue reeditado en 1604, en Barcelona y en 1605 en Madrid. Según el catálogo de venta de la biblioteca privada de Southey, ${ }^{48}$ el escritor inglés poseía la segunda edición de esta obra, la publicada en Barcelona, y posiblemente es ésta la que compró durante su estancia en España y la que leyó atentamente para realizar su análisis de La hermosura en sus Letters. Esto explicaría el hecho de que en Letters, aparte de La hermosura, Southey cite uno de los sonetos de Rimas y haga algún comentario sobre La Dragontea.

En tiempos de Lope sus poemas largos no tuvieron muy buena recepción y solo las Rimas fueron más tarde reeditadas. La hermosura no fue tan

46 Edward Churton, Gongora: An Historical and Critical Essay on the Times of Philip III \& V of Spain. With Translations (London: John Murray, 1862), vii.

47 Véase Tim Fulford, 'Heroic Voyages and Superstitious Natives: Southey's Imperialist Ideology', Studies in Travel Writing, 2 (1998), 46-64.

48 Sotheby, Catalogue of the Valuable Library of the Late Robert Southey, 195. 
exitosa como Lope esperaba y sufrió duras críticas en el momento en que fue publicada. Además, los escasos trabajos académicos que han estudiado esta obra ofrecen por lo general una opinión negativa basada en la falta de unidad, la multiplicidad de los argumentos y la simpleza de la caracterización. ${ }^{49}$ Como veremos a continuación. Southey también es muy crítico con $L a$ hermosura, coincidiendo en sus argumentos con la opinión académica generalizada. Es muy ilustrativo de la escasa atención crítica recibida por $L a$ hermosura el hecho de que las dos únicas ediciones críticas modernas de la misma hayan sido publicadas tan solo hace una década. ${ }^{50}$

En su 'Analysis', Southey cae en la inevitable comparación de la obra de Lope con el Orlando de Ariosto. En el 'Prólogo del autor' a La hermosura de Angélica, Lope cita en el italiano original la conocida estrofa número 16 del canto 30 de la obra de Ariosto, donde el autor italiano encomienda a otros ingenios la narración en verso de los episodios sucedidos a Angélica y Medoro, para después anunciar que acepta la invitación de su autor para continuar la historia:

[...] pues como en todo su Orlando no tenga cosa más notable que el suceso de Angélica, argumento y sujeto de su Furioso, y ésta dejase casada con Medoro, y advirtiese que otros los proseguirían, aunque imposible, con mejor plectro, como él por humildad dice. Yo, aficionado a su poema, libre y deseoso de saber lo que adelante le había sucedido a Angélica, hallé que la mayor parte fue en España y, por comunicarlo a todos los deseosos de aquel suceso ... ejercité la pluma.

(La hermosura de Angélica, 185)

Tal y como Pratt señala, es posible que una de las razones que atrajese a Southey de esta obra de Lope fuese precisamente la relación de ésta con la obra de Ariosto, dado que con tan solo diez años Southey ya planeaba realizar una imitación de Orlando furioso. ${ }^{51}$ Esta admiración del inglés por la obra de Ariosto supone, de partida, una lectura especialmente exigente de la obra que pretende ser su continuación. De hecho, el 'Analysis of La Hermosura de Angelica, An Heroic Poem, By Lope de Felix de Vega Carpio' (Letters, 13167) comienza haciendo referencia a los antecedentes de La hermosura en Ariosto y a su admiración por Orlando:

49 Sobre la escasa crítica existente en relación a La hermosura de Angélica, veáse la introducción de Marcella Trambaioli, en Lope de Vega, La hermosura de Angélica, ed., intro. \& notas de Marcella Trambaioli (Pamplona: Univ. de Navarra/Madrid: Iberoamericana/Frankfurt am Main: Vervuet, 2005), 9-144 (pp. 17-22). Todas las citas en el trabajo serán de esta edición.

50 Lope de Vega, Poesía, ed., intro. \& notas de Antonio Carreño, 6 vols (Madrid: Fundación José Antonio De Castro, 2002-2005), I, La Dragontea. Isidro. Fiestas de Denia. La hermosura de Angélica; y Lope de Vega, La hermosura de Angélica, ed. Trambaioli (véase nota 40, arriba).

51 Southey, Poetical Works 1793-1810, ed. Pratt, Fulford \& Roberts, V, xiv. 
What poetical mind has not been fascinated with the magic of Ariosto? This wild and wonderful Author, after leading the reader through fortysix cantos, leaves him to regret that the work is so soon concluded.

(Letters, 123)

A continuación, se refiere a los numerosos autores italianos que, siendo admiradores de la obra de Ariosto, han intentado con poco juicio escribir una continuación; y a aquellos otros, más juiciosos a su parecer, que han elaborado obras completas en sí mismas pero que tienen conexión con Orlando. Entre ellos, Southey destaca a Lope de Vega:

But of all those who have followed the path that led the Italian poet to immortality, Lope de Vega himself is the most celebrated. Confident of his own Powers he has attempted to rival Tasso in his Jerusalem Conquistada, and Ariosto in The Beauty of Angelica. An account of this poem will make the reader acquainted with the manner, the merits, and the faults of Lope de Vega. (Letters, 133)

En la Introducción a su edición de La hermosura de Angélica, Marcella Trambaioli llega a la conclusión de que Lope era consciente de que ya no podía escribir una continuación del Orlando de Ariosto y que, en su lugar, 'hizo lo único que quedaba por hacer: redactar una obra ecléctica, de aventuras y de álgidos momentos líricos'. También afirma que cualquier intento de hacer un estudio crítico del poema de Lope partiendo de la obra de Ariosto está abocado al fracaso debido a que, en su parecer, a pesar de que resulta útil ver qué motivos y recursos literarios ariostescos usa el Fénix en su poema, estos solo han de ser estudiados 'para ver cómo él los elabora y transforma'. ${ }^{52}$ Creemos que Southey no dio ese paso en su análisis de $L a$ hermosura, sino que lo leyó bajo el exigente prisma de su admiración por la obra de Ariosto, lo que sin duda determinaría las conclusiones a las que llegó.

En una carta enviada a Grosvenor Bedford, comenzada en diciembre de 1795 y enviada en febrero 1796, solo dos meses después de su llegada a España, Southey declara con orgullo: 'I read the two languages with facility, $\&$ am now abridging the Angelica of Lope de Vega'. ${ }^{53}$ En efecto, al llegar a España, Southey se propone hacer una versión reducida del extenso poema de Lope, y en su análisis incluye una selección de pasajes, seguidos de su propia traducción al inglés de siete de los doce cantos que conforman $L a$ hermosura de Angélica. Para el resto de los cantos, Southey ofrece breves resúmenes.

El lector de Letters puede fácilmente llegar a la conclusión de que Southey, que emprendió la lectura de La hermosura de Angélica con una excelente predisposición dada su manifiesta admiración por Lope, pronto se

52 Trambaioli, 'Introducción', en Lope de Vega, La hermosura de Angélica, ed. Trambaioli, 140 .

53 The Collected Letters of Robert Southey, ed. Pratt, Fulford \& Packer, I, 45. 
sintió decepcionado y, en lugar de seguir extractando y traduciendo pasajes del poema, optó finalmente por resumir el resto del mismo. Southey muestra su decepción muy pronto. Tras la traducción de los primeros versos que cita, pertenecientes al Canto I, el poeta inglés sentencia: 'Surely the man who attempted to rival Ariosto ought not to have imitated him' (Letters, 136).

La siguiente tabla recoge las secciones citadas y traducidas, además de las parafraseadas directamente en inglés por Southey, de cada uno de los cantos de La hermosura de Angélica en Letters. Se indica la página de Letters en la que aparece la cita en español o la paráfrasis en inglés:

\section{<INSERT TABLE 2 BELOW THIS HEADING>}

Tabla 2

Pasajes citados literalmente y traducidos o parafraseados en inglés $[\mathrm{P}]$ en

Letters (1797) de La hermosura de Angélica, con indicación de página en la que aparece.

'Such is the Poem which Lope de Vega produced to emulate Ariosto!' (Letters, 165; nuestro énfasis), afirma Southey como conclusión de su resumen de La hermosura y como punto de partida del comentario crítico que sigue a continuación. Con esta declaración, Southey deja claro que ha leído el poema del Fénix como una imitación del de Ariosto. De hecho, hay un momento en el que Southey está resumiendo parte del Canto IV en el que se presenta a Rolando, uno de los personajes, como 'Prince of Hungary, the son of Zerbino and Isabella' (Letters, 142), ante lo que no puede evitar incluir una nota al pie criticando la falta de fidelidad o conocimiento, o ambas cosas, de Lope ante la obra de Ariosto: 'How came Lope de Vega to forget that Isabella died a Virgin, when so very singular a part of the Orlando Furioso particularly treats of her death?' (Letters, 142).

Para empezar su análisis, Southey cuestiona la clasificación de $L a$ hermosura como poema épico, género al que sí pertenece Orlando furioso. A su parecer, el poema de Lope carece de la unidad de acción que define el género épico y que caracteriza a la obra de Ariosto a pesar de los numerosos argumentos que se entrelazan en ella. Por lo tanto, según el inglés, el poema de Lope pertenecería más bien al género de poesía heroica. En este sentido, Southey continúa, si lo comparamos con los poemas de Lucano, Boyardo, Ariosto o Spencer, el de Lope es: 'lamentably inferior [...] in design and execution [...] The Spaniard appears to have begun his poem without knowing how he should conclude it' (Letters, 165). Dos décadas más tarde, en 1818, Southey volvería a subrayar esta carencia de La hermosura en el Quarterly Review, describiendo el poema como 'loose and rambling'. ${ }^{54}$ Felipe

54 [Robert Southey], 'Some Account of the Lives and Writings of Lope Felix de Vega Carpio, and Guillen de Castro by Henry Richard Lord Holland', The Quarterly Review, XVIII:35 (1818), 1-46 (p. 37). 
Pedraza Jiménez reconoce que en esta obra el Fénix 'no consigue dibujar con nitidez las fuerzas argumentales'. En concreto, con respecto a la obra que nos ocupa, Pedraza Jiménez afirma que en ella 'subsiste el deseo de dar complejidad al relato, se enhebran aventuras, aparecen y desaparecen personajes', lo que desemboca en que suceda 'lo peor que puede ocurrir en una obra narrativa: que el lector, incluso el lector atento, acaba sin saber qué sucede en la obra'. ${ }^{55}$ Southey debió de ser uno de estos lectores atentos.

$\mathrm{Su}$ crítica con respecto a la caracterización continúa en la misma línea. Southey afirma que 'his characters are equally prominent and equally uninteresting', apostillando irónicamente 'except indeed Cardiolo, who is asleep during twelve Cantos of the Poem', lo que le lleva a concluir que en $L a$ hermosura 'there is no discrimination of character, no knowledge of human feelings; the praise of easy versification is all that it deserves' (Letters, 166). Pero, quizás, la crítica más dura, proviniendo de un poeta romántico, es la que a continuación Southey hace del poema. Más allá de aspectos formales, el joven autor señala:

Through the whole Poem I do not recollect one solitary touch of Nature.

It is the knowledge of human nature and its feelings that forms the Poet; without this he may indeed mould the Promethean statue of Clay, but where is the spirit that shall animate it? (Letters, 167)

Mucho podríamos escribir aquí sobre aspectos centrales de la poética romántica que aparecen encapsulados en este pasaje, aunque nos hemos de ceñir a limitaciones de espacio y al objetivo de este trabajo. Por ello, baste quizás con subrayar cómo la contemplación e interacción con el mundo natural tiene un carácter máxime subjetivo para los románticos, suponiendo una puerta de entrada hacia la propia esencia de la naturaleza humana, que estos autores conciben como la principal inspiración y objetivo último de la labor del poeta. En este sentido, en el Prefacio de 1800 a Lyrical Ballads, considerado a menudo como el manifiesto por excelencia de este movimiento literario, además de situar el origen de la poesía en la explosión de sentimientos producidos ante la recreación tranquila de recuerdos de emociones pasadas, a la pregunta 'What is a Poet?', Wordsworth responde precisamente que un poeta

[...] is a man speaking to men: a man [...] endued with more lively sensibility, more enthusiasm and tenderness, who has a greater knowledge of human nature, and a more comprehensive soul, than are supposed to be common among mankind. ${ }^{56}$

55 Felipe B. Pedraza Jiménez, El universo poético de Lope de Vega (Madrid: Ediciones el Laberinto, 2003), 72.

56 William Wordsworth \& Samuel Taylor Coleridge, Lyrical Ballads, ed., intro. \& notas de Michael Mason (Harlow: Pearson-Longman, 2007 [1 ${ }^{\text {st }}$ ed. Bristol: Printed by Biggs and Cottle, for T. N. Longman, 1798], 70-71. 
De hecho, siguiendo una línea de argumentación similar a la de Southey en sus conclusiones sobre La hermosura, Wordsworth afirmaría años más tarde que las principales características de un poeta eran esencialmente 'Imagination in the true sense of the word, and knowledge of human Nature and the human heart'. ${ }^{57}$ En este contexto, la afirmación de Southey con respecto a la falta de 'one solitary touch of Nature' en el poema es terriblemente demoledora. Con esta dura sentencia, Southey finaliza su análisis de La hermosura.

A continuación, Southey comenta brevemente otras obras de Lope que, a la vista de lo que escribe, no llegó a leer al completo por no ser de su gusto. Se trata de La Dragontea y Arcadia. Con respecto a la primera, en la que Lope narra los actos de piratería de Francis Drake, sus empresas navales y su derrota frente a los españoles, Southey dice: 'I have looked into his Dragontea, but found no inducement to see Sir Francis Drake butchered with such clumsy barbarity' (Letters, 166). No es de extrañar que el poeta inglés tuviese esta opinión de La Dragontea, un texto que, además de su irregular calidad literaria y sus imprecisiones históricas, se presenta por parte de Lope como una cruzada contra la Inglaterra luterana, que es finalmente vencido por la España católica. ${ }^{58}$ La novela pastoral Arcadia tampoco sale bien parada del escrutinio de Southey, quien confiesa: 'I began his Arcadia, but [...] I was not able to persevere through the little volume of Lope de Vega's pastoral prose' (Letters, 166-67). Para concluir, Southey vuelve al mismo punto donde comenzó el ensayo dedicado al Fénix de los Ingenios declarando, por medio de una fantástica metáfora, la superioridad de los sonetos frente a la poesía más extensa de Lope:

In his smaller pieces, however, he is generally tolerable and sometimes excellent. When he had found a good thought for a sonnet, the nature of that composition prevented him from spoiling it. Though his Pegasus could not accomplish a long journey, he carried his master easily enough on an evening ride. (Letters, 167; nuestro énfasis)

\section{IV}

A lo largo de los aproximadamente once años que transcurrieron entre la primera y la tercera edición de Letters Written During a Short Residence in Spain and Portugal, el interés y la fascinación de Southey por todo lo español creció considerablemente. Así, en las dos ediciones siguientes publicadas en 1799 y 1808, y muy especialmente en la última, se suavizan las primeras impresiones negativas del joven poeta que viajó a través de la Península

57 The Letters of William and Dorothy Wordsworth, arranged \& edited by the late Ernest de Selincourt, 8 vols (Oxford: Clarendon Press, 1967-1993 [1 ${ }^{\text {st }}$ ed. 1935-1939]), I The Early Years: 1787-1805, revised by Chester L. Shaver, 595.

58 María Luisa García Rodrigo, 'Algunas notas sobre la piratería en La Dragontea de Lope de Vega', Studia Aurea, 1 (1993), 329-37. 
Ibérica en 1795-1796. De hecho, la edición de 1808 refleja las ideas cuidadosamente fundamentadas y contrastadas del Southey que, después de haber leído extensamente sobre la literatura, cultura y política de España y Portugal, además de haber visitado la Península de nuevo en 1801, veía a las dos naciones ibéricas bajo una nueva y más positiva luz. En retrospectiva, el inglés cayó en la cuenta de que su tiempo en la península ibérica no había sido tan desagradable como describe por momentos en las Letters de 1797, así como de que su proclamación inicial sobre la relativa mediocridad de la literatura española en general, y de Lope en particular, había sido quizás demasiado prematura.

De esa manera, en una carta enviada a su hermano Thomas a comienzos de noviembre de 1797, apenas diez meses tras la publicación de Letters, Southey proclama cómo 'my Letters are all sold', y le informa de que las negociaciones iniciales para producir una segunda edición ya están en marcha. ${ }^{59} \mathrm{Su}$ publicación se retrasaría hasta 1799 , y si bien el texto no incorporó revisiones tan significativas como la tercera y última edición de 1808, cabe destacar que Southey tuvo cuidado de omitir tanto el 'Essay on the Poetry of Spain and Portugal', como el comentario crítico y traducción de La hermosura de Angélica. Puesto que las principales omisiones que presentaba esta segunda edición eran precisamente el 'Essay' y el comentario sobre Angélica, junto con algunas anécdotas algo lúgubres que amigos y parientes le habían aconsejado retirar, existen motivos para argumentar que Southey era consciente de que sus juicios iniciales sobre Lope y las letras españolas habían sido demasiado impulsivos. De hecho, cuanto más leía de Lope, menos crítica se volvía la actitud de Southey hacia el Fénix y su obra. Tanto es así que en 1807 llegaría a afirmar en el Annual Review, en contraste con su valoración de La hermosura de Angélica en 1797, que esta obra lopesca 'contains many spirited passages, and is certainly of all Lope's long poems, that which may be read with most pleasure', si bien la ambivalencia que caracteriza a Southey no le permitiría resistirse a añadir una coletilla sarcástica: 'or perhaps more accurately speaking, with least fatigue'. ${ }^{60}$

Este cambio de actitud progresivo hacia la literatura y cultura españolas es precisamente uno de los motivos que llevaron a Southey a producir una tercera y definitiva edición de sus Letters. La visión de una sociedad y cultura extranjeras que Southey proporcionó a los lectores ingleses ofrecía un ejemplo contra el cual reconsiderar el carácter nacional, así como los problemas contemporáneos que afectaban a las gentes de Gran Bretaña. Southey reanudaría esta tarea en 1807 , mientras trabajaba en la tercera edición de Letters Written During a Short Residence in Spain and Portugal, a través de la producción de otra narrativa de viajes, Letters from England by Don Manuel Alvarez Espriella. Esta última es una pseudotraducción de

59 The Collected Letters of Robert Southey, ed. Pratt, Fulford \& Packer, I, 269.

60 [Southey], 'Some Account of the Life and Writings of Lope Felix de Vega Carpio by Henry Richard Lord Holland', 399. 
una serie de cartas escritas por un supuesto viajero español a lo largo de su ruta por Inglaterra, que le permitió a Southey adoptar la perspectiva de un visitante extranjero para ofrecer una crítica constructiva de la sociedad británica al compararla con su homóloga ibérica. ${ }^{61}$

Aún con todo, la edición de 1797 de Letters tuvo un papel importante en la transmisión cultural y literaria de España en la Inglaterra de finales de siglo XVIII, y es de especial interés en el caso de la recepción de la obra y figura del Fénix en suelo británico. A la vista del papel central que ocupa Lope en las Letters de 1797, esta publicación resulta fundamental para entender la pervivencia del Fénix en la Inglaterra del siglo XIX.

Uno de los postulados fundamentales de la teoría de la pervivencia literaria—o teoría de la 'afterlife', en inglés—radica en que el mero hecho de que el nombre de un autor sea difundido de manera periódica en diferentes foros y a través de diversos medios maximiza la presencia pública de tal escritor, hasta el punto de que dicho recuerdo cotidiano promueve, al menos, un acercamiento gradual a sus obras, que sienta las bases de su futura pervivencia en un sistema literario concreto. ${ }^{62}$ Esto es así incluso si dicha difusión conlleva únicamente un recuerdo cotidiano del autor en cuestión, derivado de la repetición recurrente de su nombre, pero sin que el público tenga acceso de primera mano a sus escritos. De hecho, dentro de la teoría de la pervivencia literaria se conoce a los grupos de personas que mantienen viva y promueven la reputación de un autor sin haber tenido la oportunidad de leer su obra como 'nonreaders' o 'no lectores', término acuñado por Heather Jackson. ${ }^{63}$ Como el propio Southey lamentaba, éste había sido esencialmente el único conocimiento del Fénix que el público inglés había tenido hasta principios de siglo XIX:

[...] no name among the Spanish poets is so generally known out of its own country as that of Lope de Vega, but it is only the name; and perhaps no author whose reputation is so widely extended has been so little read. 64

El objetivo principal detrás de cada uno de los escritos de Southey que giraban en torno a la figura de Lope era precisamente el de sembrar las semillas de su pervivencia en suelo británico, tratando de promover un mayor

61 Véase Carol Bolton, 'Through Spanish Eyes: Robert Southey's Double Vision in Letters from England: By Don Manuel Alvarez Espriella (1807)', Victoriographies, 2:1 (2012), $1-14$.

62 Ann Rigney, The Afterlives of Walter Scott: Memory on the Move (Oxford: Oxford U. P., 2012), 18. Véanse también de acuerdo con esto Leo Braudy, The Frenzy of Renown: Fame and Its History (New York: Vintage, 1997); y Andrew Bennett, Romantic Poets and the Culture of Posterity (Cambridge: Cambridge U. P., 1999).

63 Heather Jackson, Those Who Write for Immortality: Romantic Reputations and the Dream of Lasting Fame (Yale: Yale U. P., 2015), 220.

64 [Southey], 'Some Account of the Lives and Writings of Lope Felix de Vega Carpio, and Guillen de Castro by Henry Richard Lord Holland', 1; nuestro énfasis. 
acercamiento gradual a su obra. De acuerdo con esto, recordemos que en Letters Southey reproduce y traduce el soneto XXXIX de Rimas, aduciendo ciertamente cómo 'I will give you some specimens of his merit and manner, from which you may judge whether or not the character I draw of him be just' (Letters, 119); o el hecho de que en su reseña de 1807 para el Annual Review, tras lamentar cómo el Fénix había sido 'criticised in the most contemptuous and dogmatical manner, by a writer who did not know how to spell his name', Southey defendía 'that it should no longer be excusable for Englishmen to be ignorant [of Lope de Vega]'. ${ }^{65}$

De hecho, además de su estudio crítico de Lope y La hermosura de Angélica para las Letters de 1797, los proyectos más relevantes en los que Southey se embarcó en su estudio del Fénix fueron precisamente sus reseñas de la primera y segunda edición del prestigioso volumen crítico que Lord Holland publicó en 1806, y de nuevo en 1817 en una edición revisada y ampliada, Some Account of the Life and Writings of Lope Felix de Vega Carpio. Estos dos trabajos, que recordemos Southey publicó en el Annual Review y en el Quarterly Review, bien podrían ser el tema central de un artículo en sí mismos, en especial el segundo de ellos. Escrito en la revista literaria y política más importante del siglo XIX, este trabajo seguía un patrón formal que Southey emplearía en la mayor parte de sus reseñas, ya establecido por los colaboradores de la otra publicación más relevante de la época, el Edinburgh Review. Se trataba de tomar un libro y luego escribir un ensayo independiente sobre el tema, que a menudo únicamente ofrecía un vistazo superficial al volumen que en teoría se estaba reseñando. ${ }^{66}$ En este caso concreto, el libro de Holland constituyó en cierta medida una mera excusa que le dio la oportunidad a Southey de ahondar en todos los aspectos de la vida y obra de Lope que le resultaban más interesantes, y que Holland había dejado fuera de su volumen, incluso en su versión revisada y expandida.

Tanto es así que cuando John Murray, editor de el Quarterly Review, le consultó a Southey si estaría dispuesto a reseñar la segunda edición de 1817 tras su trabajo para el Annual Review, su respuesta fue precisamente: 'I reviewed the first edition of Ld Hollands book,- - but I can very well review an enlarged edition without repeating myself ${ }^{67} \mathrm{En}$ su correspondencia privada, Southey se enorgullecería en este sentido sobre cómo su 'article upon Lope de Vega' para el Quarterly Review, 'besides a good many translations, will from his own writings establish certain facts in his history that have escaped Lord Holland \& all his other biographers'. ${ }^{68}$ De este modo, en 1818

65 [Southey], 'Some Account of the Life and Writings of Lope Felix de Vega Carpio by Henry Richard Lord Holland', 397.

66 John O. Hayden, The Romantic Reviewers. 1802-1824 (London: Routledge, 1969), 7 8.

67 The Collected Letters of Robert Southey, ed. Pratt, Fulford \& Packer, V, 2697.

68 The Collected Letters of Robert Southey, ed. Pratt, Fulford \& Packer, V, 3026. 
vio la luz un trabajo inédito de cuarenta y seis páginas, que además incluía una veintena de traducciones propias de aquellos poemas de Lope que Southey consideraba más representativos para ilustrar sus argumentos. Como argumenta Jackson, para comprender la recepción y pervivencia de un autor y su obra, especialmente fuera del sistema literario de su país de origen, es necesario ir más allá de la evaluación de la disponibilidad de los propios textos, puesto que la recepción de obras literarias no existiría sin la mediación de diferentes agentes que promueven el acercamiento de lectores y autores. En este sentido, junto con la reimpresión y reedición de sus obras y la supervisión de su recopilación, para extender la fama de un autor son necesarios agentes que escriban la vida y evalúen periódicamente el mérito del mismo. 69

La difusión del Lope y su obra que Southey inicia formalmente con sus Letters en 1797 resultó así fundamental para la pervivencia del Fénix y sus textos que se observa en Inglaterra a lo largo del siglo XIX. Dados los límites del presente trabajo, y puesto que se trata de un campo todavía por explorar, a modo de ilustración baste quizás con mencionar la publicación en Londres entre 1817 y 1820 de El teatro español, una antología multivolumen que popularizó tres dramas de Lope: La moza del cántaro (1618), El mejor alcalde el rey (1623) y Por la puente, Juana (1635); o destacar algunos prominentes semanarios británicos que se encargaron de promover el interés por la obra del Fénix, como The British Review and London Critical Journal, The Quarterly Review, The St. James's Magazine, o Household Words, la prestigiosa revista editada por Charles Dickens en la década de 1850.70

69 Jackson, Those Who Write for Immortality, 22.

70 El teatro español, o colección de dramas escogidos de Lope de Vega, Calderón de la Barca, Moreto, Roxas, Solís y Moratín; precedida de una breve noticia de la escena española y de los autores que la han ilustrado, ed. Ángel Anaya, 4 vols (London: Smallfield, 1817-1820). Sobre la presencia de Lope en los semanarios británicos mencionados arriba, véanse, por ejemplo, John Mason Good, 'Sismondi on Spanish Literature', The British Review and London Critical Journal, VII (1816), 155-90; Anón., 'El teatro español, o colección de dramas escogidos de Lope de Vega, Calderón de la Barca, Moreto, Roxas, Solis y Moratín; precedida de una breve noticia de la escena Española y de los autores que la han ilustrado', The Quarterly Review, LIX:117 (1837), 62-87; Robert Barnabus Brough, 'Something Like a Dramatic Author', Household Words, XII:283 (25 August 1855), 93-96; o B. B., 'Early Spanish Playwrights', The St. James's Magazine, XIV (August 1865), 24-30.

* Cláusula de divulgación: los autores han declarado que no existe ningún posible conflicto de intereses. 
Tabla 1

Relación de autores y obras poéticas citadas y traducidas en Letters $(1797)^{33}$

\begin{tabular}{|c|c|c|c|c|}
\hline $\begin{array}{l}\text { Titulo según aparece } \\
\text { en el index }\end{array}$ & Título original & $\begin{array}{c}\text { Información sobre el } \\
\begin{array}{c}\text { autor según aparece } \\
\text { en el index }\end{array}\end{array}$ & Autor & $\begin{array}{c}\text { Idioma } \\
\text { original }\end{array}$ \\
\hline Epitaph on an Astrologer & $\begin{array}{l}\text { 'Epitaph. In Pseudoprophet. Marcolphum', } \\
\text { en La Silva Curiosa de Julián de Medrano } \\
(1583)\end{array}$ & & anónimo & Español \\
\hline The musical Ass & $\begin{array}{l}\text { 'El burro flautista', en Fábulas literarias } \\
(1782)\end{array}$ & Yriarte & $\begin{array}{l}\text { Tomás Iriarte } \\
(1750-1791)\end{array}$ & Español \\
\hline To a Lock of Hair & $\begin{array}{l}\text { Extracto de Los siete libros de la Diana } \\
(1559)\end{array}$ & George of Montemayor & \begin{tabular}{|l|} 
George de \\
Montemayor \\
$(1520-1561)$ \\
\end{tabular} & Español \\
\hline Sonnet & & Lope de Vega & \begin{tabular}{|l} 
Lope de Vega \\
$(1562-1635)$
\end{tabular} & Español \\
\hline $\begin{array}{l}\text { Extracts from 'The Beauty of } \\
\text { Angélica' }\end{array}$ & La hermosura de Angélica (1602) & Lope de Vega & $\begin{array}{l}\text { Lope de Vega } \\
(1562-1635)\end{array}$ & Español \\
\hline Epigram on the Real Presence & 'Al propio asunto' & Luis de León & $\begin{array}{l}\text { Fray Luis de León } \\
(1527-1591)\end{array}$ & Español \\
\hline Sonnet on the Real Presence & 'Si pan es lo que vemos' & Luis de León & $\begin{array}{l}\text { Fray Luis de León } \\
(1527-1591)\end{array}$ & Español \\
\hline $\begin{array}{l}\text { Extempore lines on quitting } \\
\text { the Inquisition }\end{array}$ & 'Aquí la envidia y mentira' & Luis de León & $\begin{array}{l}\text { Fray Luis de León } \\
(1527-1591)\end{array}$ & Español \\
\hline To Zephyrus & 'Al Cefiro' & $\begin{array}{l}\text { Esteban Manuel de } \\
\text { Villegas }\end{array}$ & $\begin{array}{l}\text { Esteban Manuel de } \\
\text { Villegas } \\
(1589-1669) \\
\end{array}$ & Español \\
\hline $\begin{array}{l}\text { Dialogue between an Athenian } \\
\text { Philosopher and a Christian } \\
\text { Theologian }\end{array}$ & $\begin{array}{l}\text { 'Diálogo entre un Filósofo ateniense y un } \\
\text { teólogo cristiano' }\end{array}$ & Alonso de Ledesma & $\begin{array}{l}\text { Alonso de Ledesma } \\
(1562-1623)\end{array}$ & Español \\
\hline Sonnet & $\begin{array}{l}\text { ‘Quita este afeyte, Lais, que se ceda’ (Rima } \\
\text { XXI) }\end{array}$ & Bartolome Leonardo & $\begin{array}{l}\text { Bartolome Leonardo } \\
\text { de Argensola } \\
(1562-1631) \\
\end{array}$ & Español \\
\hline
\end{tabular}

33 No incluimos en la tabla los poemas originales compuestos por Robert Southey por no ser el objeto central de estudio en este trabajo: 'Retrospective Musings', 'Lines Written on Monte Salgueiro', 'Sonnet: Another mountain yet! I thought this brow', 'Lines upon the Widow of Villa Franca', 'Lines upon Christmas Day', 'Inscription for a Monument, where Juan de Padilla Suffered Death', 'Inscription for a Column at Truxillo, 'Ode: When at morn, the muleteer', y 'Musings after visiting the Convent of Arrabida'. Estos poemas han sido editados recientemente en Southey, Poetical Works 1793-1810, ed. Pratt, Fulford \& Roberts, V, 138-52.

\begin{tabular}{|c|c|c|c|c|}
\hline $\begin{array}{l}\text { Título según aparece } \\
\text { en el índex }\end{array}$ & Título original & $\begin{array}{c}\text { Información sobre el } \\
\begin{array}{c}\text { autor según aparece } \\
\text { en el index }\end{array} \\
\end{array}$ & Autor & $\begin{array}{c}\text { Idioma } \\
\text { original }\end{array}$ \\
\hline $\begin{array}{l}\text { Inscription of a Bust of } \\
\text { Danton, imitated From } \\
\text { Gongora }\end{array}$ & $\begin{array}{l}\text { Free translation (imitated) from 'A la } \\
\text { Muerte de D. Rodrigo Calderón'- 'Este, que } \\
\text { en la fortuna más subida' }\end{array}$ & Góngora & $\begin{array}{l}\text { Luis de Góngora } \\
(1561-1627)\end{array}$ & Español \\
\hline Ode & Oda VII. 'Profecía del Tajo' & Luis de Leon & $\begin{array}{l}\text { Fray Luis de León } \\
(1527-1591)\end{array}$ & Español \\
\hline Madrigal & 'Retrato de Lisis en mármol' & Quevedo & $\begin{array}{l}\text { Francisco de Quevedo } \\
(1580-1645)\end{array}$ & Español \\
\hline Madrigal to St. Stephen & $\begin{array}{l}\text { 'Santo Estevam Proto-Martyr, Esculpido en } \\
\text { huma pedra' }\end{array}$ & Jeronymo Bahia & $\begin{array}{l}\text { Jerónimo Baía } \\
(1620-1688)\end{array}$ & Portugués \\
\hline Extracts from Carlos Reduzido & $\begin{array}{l}\text { Extractos de Carlos Reduzido, Inglaterra } \\
\text { illustrada (1716) }\end{array}$ & & $\begin{array}{l}\text { Pedro de Azevedo } \\
\text { Tojal } \\
(16 ? ?-1742)\end{array}$ & Portugués \\
\hline To a Stream & 'A un arroyuelo' & Villegas & $\begin{array}{l}\text { Esteban Manuel de } \\
\text { Villegas } \\
(1589-1669)\end{array}$ & Español \\
\hline Old Spanish Ballad & $\begin{array}{l}\text { Poem 'Ocho a ocho, diez a diez', en Historias } \\
\text { Civiles de Granada (1660) }\end{array}$ & & Anónimo & Español \\
\hline $\begin{array}{l}\text { Inscription for a Tablet near } \\
\text { the Arrabida Convent }\end{array}$ & 'Al combento devotissimo de la Arrabida' & Francisco Manuel & $\begin{array}{l}\text { Francisco Manuel de } \\
\text { Melo } \\
(1608-1666) \\
\end{array}$ & Portugués \\
\hline Extract from the Caramuru & Extract from 'Caramuru' & & $\begin{array}{l}\text { Frei José de Santa } \\
\text { Rita Durão } \\
(1722-1784)\end{array}$ & Portugués \\
\hline Sonnet & 'En vous disant adieu, malgre moi je soupire' & Madame Montreul & $\begin{array}{l}\text { Jean de Montereul } \\
(1614-1651) \\
\end{array}$ & Francés \\
\hline $\begin{array}{l}\text { Epitaph on D. Joanon de } \\
\text { Castro }\end{array}$ & & & anónimo & Latin \\
\hline The Dancing Bear & $\begin{array}{l}\text { 'El oso, la mona y el cerdo', en Fábulas } \\
\text { literarias (1782) }\end{array}$ & Yriarte & $\begin{array}{l}\text { Tomás Iriarte } \\
(1750-1791)\end{array}$ & Español \\
\hline
\end{tabular}

34 Religiosa de la Abadía de Montereul, Convento de religiosas Ursulinas. 
Tabla 2

Pasajes citados literalmente y traducidos o parafraseados en inglés [P] en Letters (1797) de La hermosura de Angélica, con indicación de página en la que aparece.

\begin{tabular}{|c|c|c|}
\hline \multicolumn{2}{|c|}{$\begin{array}{c}\text { La hermosura de Angélica } \\
\text { Pasajes citados y traducidos o parafraseados en inglés [P] }\end{array}$} & \multirow{2}{*}{$\begin{array}{c}\begin{array}{c}\text { Letters } \\
\text { Página }\end{array} \\
134 \\
134 \\
134\end{array}$} \\
\hline Canto I & $\begin{array}{l}\text { I.52. ll. } 409-16 \\
\text { I.54. ll. } 425-32 \\
\text { I.55. ll. } 433-40\end{array}$ & \\
\hline Canto III & $\begin{array}{l}\text { III.14. ll. 111-12 } \\
\text { III.25. ll. 198-200 [P] } \\
\text { III.27. ll. 209-16 } \\
\text { III.28. ll. 217-24 }\end{array}$ & $\begin{array}{l}137 \\
137 \\
137 \\
138\end{array}$ \\
\hline Canto III [cont.] & $\begin{array}{l}\text { III.29. 1l. } 225-28 \\
\text { III.55. 1l. } 433-40 \\
\text { III.56. 1l. } 441-48 \\
\text { III.57. 1l. } 449-56 \\
\text { III.58. 1l. } 457-60 \\
\text { III.60. 1l. } 473-75 \text { [P] } \\
\text { III.62. 1l. 489-92 [P] }\end{array}$ & $\begin{array}{l}138 \\
139 \\
140 \\
140 \\
140 \\
142 \\
142\end{array}$ \\
\hline Canto IV & $\begin{array}{l}\text { IV.35. ll. 273-80 } \\
\text { IV.36. ll. 281-88 } \\
\text { IV.37. ll. 289-96 } \\
\text { IV.38. ll. 297-304 } \\
\text { IV.39. ll. 305-12 } \\
\text { IV.40. ll. 313-20 } \\
\text { IV.41. ll. 321-38 } \\
\text { IV.42. ll. 329-36 } \\
\text { IV.43. ll. 337-44 } \\
\text { IV.44. ll. 345-52 } \\
\text { IV.45. ll. 353-60 } \\
\text { IV.46. 1l. 361-68 } \\
\text { IV.47. l. 379 } \\
\text { IV.49. ll. 388-89 [P] }\end{array}$ & $\begin{array}{l}143 \\
144 \\
144 \\
144 \\
145 \\
145 \\
145 \\
146 \\
146 \\
146 \\
147 \\
147 \\
150 \\
151\end{array}$ \\
\hline Canto V & $\begin{array}{l}\text { V.9. l. } 65 \\
\text { V.12. ll. 89-96 } \\
\text { V.13. 1l. 97-104 } \\
\text { V.14.1l. 105-11 } \\
\end{array}$ & $\begin{array}{l}151 \\
151 \\
151 \\
152 \\
\end{array}$ \\
\hline Canto VI & VI.48. 11. 381-82 & 154 \\
\hline Canto XI & XI.46. 1l. 361-64 & 159 \\
\hline Canto XII & XII.9. 1l. 69-72 & 159 \\
\hline
\end{tabular}

